Pediatr. Radiol. 8, 21-22 (1979)

Pediatric

\title{
Cystourethrography: The Effect of Reservoir Height upon Intravesical Pressure
}

\author{
S. A. Koff, C. P. Fischer, and A. K. Poznanski
}

Department of Surgery, Section of Urology, and Department of Radiology, Section of Pediatric Radiology, University of Michigan Medical Center, Ann Arbor, Michigan, USA

\begin{abstract}
The effect of infusion height upon intravesical pressure during cystography was studied in three dogs and three patients. Results indicate that during bladder filling the intravesical pressure is independent of the reservoir height.
\end{abstract}

Key words: Voiding cystourethrography - Bladder pressure

Voiding cystourethrography is a diagnostic radiographic study frequently used to evaluate vesico-ureteral reflux in children with recurrent urinary tract infection. It is best performed by gravity infusion of contrast media through a small caliber nonretention catheter. The radiologic literature has cautioned that the infusion reservoir be no higher than $25 \mathrm{~cm}$ [1] to $60 \mathrm{~cm} \mathrm{[2]} \mathrm{above} \mathrm{the} \mathrm{fluoroscopy} \mathrm{table} \mathrm{top} \mathrm{to} \mathrm{avoid}$ increases in intravesical pressure. In an attempt to formally assess the effects of reservoir height upon intravesical pressure, gravity infusion cystography was performed using varying reservoir heights.

\section{Materials and Methods}

Three female mongrel dogs were anesthetized with sodium pentobarbital and an $8 \mathrm{~F}$ infant feeding tube was inserted into the bladder through a suprapubic cystotomy. A $16 \mathrm{~F}$ retention catheter was introduced via the urethra. The bladder was filled to capacity with $30 \%$ Conray by gravity infusion through the $8 \mathrm{~F}$ tube. The initial reservoir height was $20 \mathrm{~cm}$. This was raised by increments of $20 \mathrm{~cm}$ and the gravity infusion repeated at each new height. A maximum height of $160 \mathrm{~cm}$ was tested. In each trial, the intravesical pressure was monitored continuously through the urethral catheter using a water monometer.

In the second portion of the study, bladder filling was initiated with the reservoir at $65 \mathrm{~cm}$. While continuously monitoring the intravesical pressure, the reservoir height was raised to $130 \mathrm{~cm}$ and returned to $65 \mathrm{~cm}$ after each $50 \mathrm{ml}$ increase in bladder volume.

In three awake adult male volunteers on chronic suprapubic catheter drainage, an $8 \mathrm{~F}$ infant feeding tube was passed urethrally and the bladder filled to capacity by constant gravity infusion of isotonic saline. Intravesical pressures were monitored through the suprapubic catheter. Individual infusions were performed at reservoir heights of $61,122,183$ and $205 \mathrm{~cm}$ in each patient.

\section{Results}

During bladder filling in dogs, the intravesical pressure was independent of reservoir height and was solely determined by bladder volume (Figure 1); even changes in reservoir position during filling did not affect bladder pressure (Figure 2). Only the speed of bladder filling was altered by reservoir position. With overdistention and cessation of flow, however, bladder pressure equilibrated with infusion pressure (reservoir height). The same observations were made in each of the adult patients.

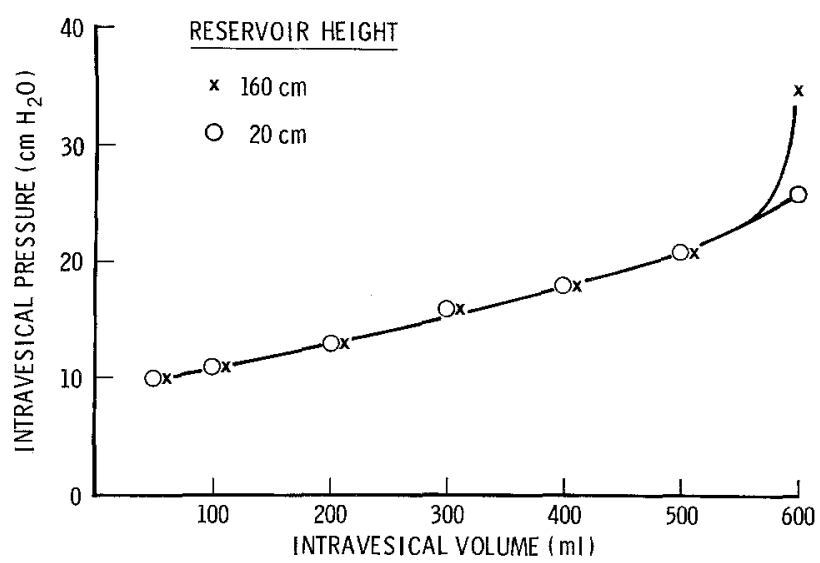

Fig. 1. Schematic cystometrograph showing the effect of different reservoir heights on intravesical pressure 


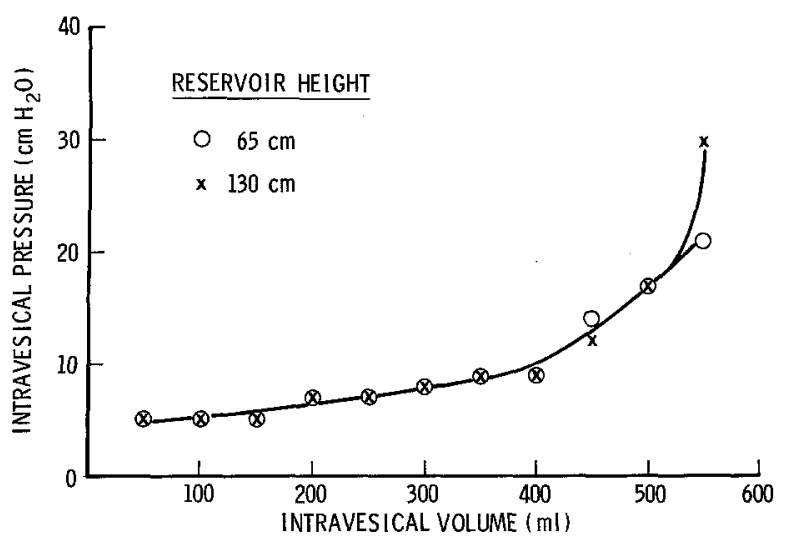

Fig. 2. Schematic cystometrograph showing the effect on intravesical pressure of changing the reservoir height from $65 \mathrm{~cm}$ to $130 \mathrm{~cm}$

\section{Discussion}

The intravesical pressure changes during infusion cystography are similar to those seen in water cystometry and reflect the smooth muscle and elastic tissue properties of the bladder. During filling, the detrusor accommodates to increasing volume and maintains low intravesical pressures [3]. When capacity is reached, intravesical pressure rises in a linear fahion due to stretching of elastic tissues. Overdistention of the bladder will increase the intravesical pressure until it equals the infusion pressure, whereupon flow will cease.

These study data indicate that during gravity filling of the bladder, the intravesical pressure is determined entirely by bladder volume and is independent of reservoir height. Filling pressure, however, does influence the flow rate and modulates the speed with which intravesical pressure changes occur. During micturition intravesical pressure is similarly independent of reservoir position and is determined by resistance to flow. High intravesical pressure, how- ever, may be generated by overdistention of the bladder or by obstruction during voiding.

The practical implication of this study is that changing the flow rate during infusion cystography will not alter the bladder pressure for any given bladder volume. Raising the height of the drip bottle will serve only to increase the speed of infusion, not the bladder pressure. Likewise, the use of wide bore catheters and tubing will neither artificially nor actually alter the intravesical pressure-volume relationship; only the rate of infusion will change. However, although bladder pressure remains solely a function of bladder volume during filling, with overdistention the intravesical pressure may equilibrate with the filling pressure when flow ceases. For this reason, reservoir heights above $100 \mathrm{~cm}$ should be avoided when capacity is near. Equilibration up to $100 \mathrm{~cm} \mathrm{H}_{2} \mathrm{O}$ is still physiological and represents the upper limit of normal for maximum voiding pressure in boys without bladder outflow obstruction [4].

\section{References}

1. Friedland, G. W.: Recurrent urinary tract infections in infants and children. Radiol. Clin. North Am. 15, 19 (1977)

2. McAlister, W. H., Cacciarelli, A., Shackelford, G. D.: Complications associated with cystography in children. Radiology 111, 167 (1974)

3. Lapides, J., Friend, C. R., Ajemian, E. P., Rems, W. F.: A new method for diagnosing the neurogenic bladder. Univ. Michigan Med. Bull. 18, 166 (1962)

4. Gierup, J.: Micturition studies in infants and children. Scand. J. Urol. Nephrol. 4, 217 (1970)

Date of final acceptance: December 13, 1978

Stephen A. Koff, M. D.

Department of Surgery

Section of Urology

University of Michigan Medical Center

Ann Arbor, MI 48109

USA 